\title{
DILEMAS ÉTICOS NO CAMPO DA VIOLÊNCIA ${ }^{1}$
}

\section{A percepção dos significados da palavra violência revela a ambigüidade característica de um sistema social pouco afeito à democracia}

O presente trabalho é uma continuidade de nossas reflexões sobre o campo da violência, e tem o Brasil contemporâneo como pano de fundo. Nas nossas pesquisas temos procurado refletir sobre a importância dos dilemas culturais no complexo conjunto de fenômenos que designamos, genericamente, como violência. Interessa-nos particularmente caracterizar a percepção que os sujeitos sociais têm da violência e sua relação com a construção de uma sociedade democrática.

Lembramos, em primeiro lugar, que a violência é uma construção social ambígua, cujo significado social está em mudança. Observa-se atualmente uma ampliação do campo semântico da palavra violência, o que não corresponde, necessariamente, a um aumento das taxas de criminalidade, contra a pessoa ou contra o patrimônio ${ }^{2}$. De fato, neste campo pressupõe-se que haja concordância, seja quanto ao seu agravamento, seja em relação às causas ou no que se refere às soluções a

\section{O AUTOR}

\section{Theophilos Rifiotis}

Professor do Departamento de Antropologia da Universidade Federal de Santa Catarina, no Programa de Pósgraduação em Antropologia Social. serem adotadas. No entanto, nem sempre as pesquisas confirmam as afirmações genéricas, e por vezes contrariam frontalmente o senso comum e o discurso da mídia.

A nossa percepção sobre a violência é ainda pouco conhecida. Fato que representa mais uma dificuldade para que os resultados das pesquisas possam ser corretamente compreendidos e possam apoiar a definição de políticas públicas eficientes. Luís Eduardo Soares se refere à violência como uma palavra-valise ${ }^{3}$, porque através dela se processa uma homogeneização de diversos fenômenos, induzindo a uma simplificação quanto às suas possíveis causas.

Ao falarmos de violência não estamos nos referindo apenas a realidades concretas, mas a um sistema de classificação e de significação que orienta a nossa percepção dos fenômenos.

Quando procuramos circunscrever o campo semântico da palavra violência, deparamo-nos com um jogo de linguagens onde diferentes tipos de fenômenos são aproximados, enredados numa teia discursiva cuja amplitude equivale a uma visão de mundo. Assim, aquilo que chamamos violência recobre fenômenos muito diferentes que não podem

\footnotetext{
1. Este texto foi elaborado a partir da comunicação apresentada no Encontro "Tendências Atuais no Estudo da Violência", organizado pelo Laboratório de Estudos da Violência (LEVIS) do Programa de Pós-graduação em Antropologia Social da UFSC, em março de 1996, com a participação de pesquisadores da UFRJ e da Universidade de Buenos Aires. Publicado na Internet: www.cfh.ufsc.br/nucleos-de-pesquisa/raiva/raiva.html

2. Para evitarmos uma simplificação desta questão, recomenda-se uma leitura dos dados coletados pelo ISER para a cidade do Rio de Janeiro: SOARES, L.E. et alii. Violência e política no Rio de Janeiro. Rio de Janeiro: Relume Dumara/ISER (Instituto Superior de Estudos da Religião), 1996. E, para dados mais gerais, particularmente sobre a Europa: CHESNAIS, J. C. Histoire de la violence en Occident de 1800 à nos jours. Paris: Robert Laffont, 1981 .

3. Entrevista concedida ao Boletim da Associação Brasileira de Antropologia, 1995, n.24. SOARES, L. E. et alii. op. cit.
} 
ser reduzidos ao crime e à violência institucional. Desse modo, no nosso cotidiano, referimo-nos à violência no esporte, no trânsito, nas ruas, nas prisões, ou ainda com relação às precárias condições de vida, à fome e, evidentemente, com relação à criminalidade; a violência contra as mulheres, contra as crianças, contra a natureza, a violência física, psicológica, simbólica, cognitiva... Esta série, cuja regra de formação ainda nos é invisível, pode englobar as relações de força, as tensões, as hierarquias, as desigualdades sociais e as situações de conflito em geral.

Acreditamos, portanto, que uma reflexão em torno das bases culturais da nossa imagem da violência pode contribuir para uma melhor compreensão desta construção social. Tomamos como ponto de partida uma linha de pesquisa que definimos provisoriamente como aceitabilidade da violên$\mathrm{cia}^{4}$. Concretamente, as nossas pesquisas têm sido orientadas para a caracterização das atitudes e juízos ambíguos frente à violência e, mais recentemente, com relação à violência policial ${ }^{5}$ no Brasil.

Em outros termos, entendemos que a violência não pode ser simplesmente negada, considerada como uma parte maldita da sociedade, um resquício do passado que deve ser eliminado: ela é um dos elementos vivos de qualquer projeto social. De um ponto de vista mais amplo, acreditamos que, ao invés de negarmos a sua presença e a repudiarmos como um fantasma, deveríamos procurar compreender como ela se inscreve nas relações sociais e no nosso imaginário. Essa atitude reflexiva poderia contribuir para um melhor conhecimento da nossa sociedade, e também para a modulação da própria violência ${ }^{6}$.

Para analisarmos os dilemas colocados pela violência e traçar-lhes um primeiro perfil, utilizaremos experiências cotidianas e cenários sociais significativos para a construção de uma sociedade democrática e plural.

Estes cenários serão extraídos de um curta-metragem ${ }^{7}$, abordando a chamada cri- $^{-}$ se de instituições e a ambigüidade frente à violência. O cenário básico será o conhecido refrão "Chame o ladrão, chame o ladrão..." da música Acorda amor!, de Chico Buarque.

\section{SE NON É VERO É BEN TROVATO}

Neste primeiro texto, tomamos como pretexto uma sequiência de cenas do curtametragem citado anteriormente, cuja discussão nos permitirá evidenciar a complexidade dos fenômenos da violência. Para analisarmos este cenário devemos nos colocar numa posição compreensiva, no sentido da sociologia de Max Weber, seguindo uma vontade de saber que se estende para além de um discurso denunciatório e de uma valorização da violência. Devemos apelar à nossa capacidade subjetiva de vivência, para que possamos dar visibilidade aos dilemas que a nossa prática social concreta encerra. Comecemos então pela descrição do cenário.

4. RIFIOTIS, Theophilos. O leitor-modelo do caso da Polícia Militar na favela Naval (Diadema). In: A denúncia da violência policial na imprensa de São Paulo. Caxambu, XXI Encontro Anual da ANPOCS, 1997. (Mimeo.)

Nos campos da violência: diferença e positividade. Florianópolis, 1996. (Publicado na home page da Raiva, a Rede Aberta de Investigações das Violências: www.cfh.ufsc.br/nucleos-de-pesquisa/raiva/raiva.htm)

5. A expressão "violência policial" é amplamente utilizada para designar atos abusivos da prática policial, deixando-se, implicitamente, entrever que poderiam ter sido evitados. Acreditamos que uma discussão mais apurada desta noção poderia nos auxiliar na reflexão sobre o papel da polícia nas sociedades democráticas. (RIFIOTIS, Theophilos, op. cit.)

6. MAFFESOLI, M. Dinâmica da violência. Revista dos Tribunais. São Paulo: Vértice, 1987.

7. Trata-se de um curta-metragem dirigido por Mauro Batista, apresentado no Seminário Linguagens da violência. Evento Multimídia sobre Violência, Comunicação e Cultura no Brasil Contemporâneo, realizado pela UFRJ/CFCH/NEPCON, em novembro de 1995, no Rio de Janeiro. 
Atenção! Câmaras... Ação!

Cena 1: Um rico empresário está sendo assaltado na sua casa.

Cena 2: Acidentalmente, ele consegue dominar $o$ assaltante.

Cena 3: Ele é ameaçado pelo assaltante, que afirma que a sua prisão será temporária e que voltará para se vingar dele e de sua família.

Cena 4: O empresário telefona para um delegado conhecido, que confirma as palavras do assaltante.

Cena 5: Ele é aconselhado, face às circunstâncias, a matar o assaltante.

Estas cenas foram relatadas e repetidas boca-a-boca como sendo um caso real. Mesmo para aqueles que não ouviram falar no caso, ele parece encerrar algo tragicamente plausível, ainda que inaceitável. A força expressiva do caso está justamente na sua verossimilhança, que fez dele um objeto de inquietação para a análise da violência no Brasil. De fato, ele se transformou em curta-metragem e está presente nas reflexões sobre violência de dois importantes psicanalistas: Contardo Calligaris e Jurandir da Costa Freire ${ }^{8}$.

O caso relatado pode ser considerado como uma narrativa cujo valor emblemático é amplificado pela omissão de nomes e de endereços, que forneceriam uma realidade desnecessária, senão excessiva. Porém, para além do jogo identificatório, a seleção dos lugares e dos personagens é uma prova da grande capacidade catalisa- dora da narrativa ${ }^{9}$. O discurso construído a partir do caso real é tão exemplar que os lugares e os personagens que lhe dão realidade são apresentados, genericamente, como São Paulo e Rio de Janeiro, ou seja, o meio urbano, paradigma da grande cidade e do rico empresário.

Transportado para o cinema, este discurso ganha uma dimensão visual e multiplica a sua capacidade de interrogativa. Os espectadores são levados a refletirem sobre uma situação limite. De um lado temos a lei, a justiça e de outro, a vingança e a defesa da vida. Entre um e outro cresce um dilema com que muitas vítimas não tiveram a ocasião de serem confrontadas e que por esta mesma razão o curta-metragem se torna um lugar privilegiado para projeções e afirmações de valores. É no amálgama produzido por estas projeções e valores que somos colocados frente a um discurso que não se propõe a explicitar a sua moral da história, apenas nos pergunta: o que faríamos nós mesmos naquelas condições? ${ }^{10}$

\section{SIGNIFICADO E CARÁTER SOCIAL}

Para caracterizar as grandes linhas deste discurso, podemos nos valer do modelo semiótico, no qual elementos narrativos variáveis e que ocupam uma mesma posição na seqüência narrativa, mantendo entre si uma homologia, são chamados actantes $^{11}$. Neste modelo, a narrativa inicia-se

8. FREIRE, Jurandir da Costa. O medo social. Veja. 25 anos, reflexões para o futuro. São Paulo: Abril, 1993.

CALLIGARIS, Contardo. Hello Brasil! Notas de um psicanalista europeu viajando ao Brasil. São Paulo: Escuta, 1991.

9. Um outro "caso" de uma mulher assaltada por um adolescente que ameaça matar o filho que a acompanhava no carro; e num outro dia, casualmente, ela vê o assaltante, que ela atropela e mata sob a aprovação dos presentes, é relatado por J. C. Freire, que considera que ela "(...) ilustra o que é a cultura da violência, a sua feição no Brasil". C. f. FREIRE, J. C. $O$ medo... op. cit. p. 83 .

10. Conforme nos referimos anteriormente, não se trata de considerar esta interrogação como uma simulação, para a qual deveríamos mobilizar exclusivamente a nossa racionalidade e os nossos princípios. $\mathrm{O}$ interessante para o pesquisador seria procurar aproximar-se da posição dos agentes sociais, identificando suas motivações e incertezas.

11. GREIMAS, A. J., COURTÉS, J. Sémiotique: Diccionnaire raisonné de la théorie du langage. (Semiótica: dicionário explicativo da teoria da linguagem.) Paris: Hachette, 1979. 
por uma ruptura inicial que leva os personagens a se alinharem em quatro posições básicas: sujeito e objeto, relacionados pelo desejo de recuperar um equilíbrio inicial quebrado; e duas posições, digamos, auxiliares: adjuvante e opositor, conforme o personagem/elemento narrativo contribua ou não para realizar o projeto do sujeito de aproximarse do objeto.

Para as cenas que estamos discutindo teríamos, inicialmente, uma ruptura do equilíbrio da vida do empresário rico e os ameaçados (ele e sua família), e de outro lado o assaltante (sem descrição, remetendo ao desconhecido). Esta situação inverte-se, colocando a vítima na posição de potencial agressor, construindo o momento crucial que é a tomada da decisão entre entregar o assaltante para a polícia ou matá-lo.

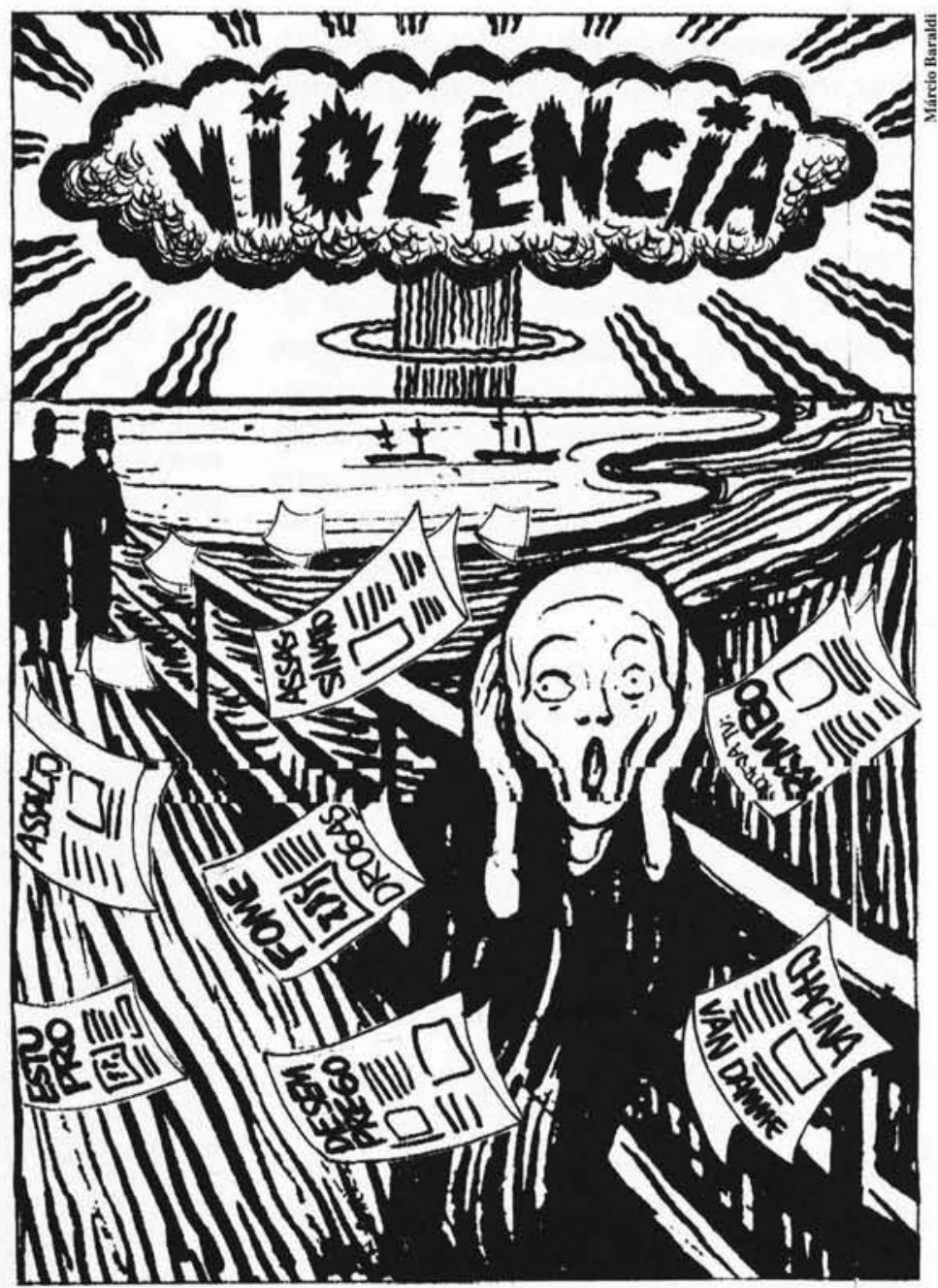

Neste cenário, o objeto desejado poderia ser traduzido em termos de segurança, de defesa do território privado, ou ainda a vingança, ou uma reação contra a impunidade. Poderia ser também qualquer sucedâneo correlato a um desejo que na narrativa possa ser atribuído ao actante sujeito. Para definirmos qual é o objeto desejado é preciso, antes de mais nada, compreendermos o que na perspectiva do sujeito (rico empresário e sua família) corresponde a um retorno ao equilíbrio inicial, desfeito pela intervenção do assaltante.

$\mathrm{O}$ assaltante atuaria como opositor, pois rompe com a situação de equilíbrio anterior. É interessante notar que na narrativa a polícia e o sistema judiciário, uma vez que estão sendo relacionados com a impunidade e a incapacidade de impedir que se criasse a disjunção inicial, estariam também na posição de opositor.

Portanto, chegamos a um ponto em que não se pode aceitar a idéia simplista de que matar o assaltante é uma vingança, pois para o sujeito este parece ser o único modo pelo qual ele prevê a reconquista do equilíbrio perdido. 
$O$ recurso à semiótica permite identifịcar as motivações próprias dos personagens expressas no discurso.

Desse ponto de vista, quando é o empresário que domina o assaltante, ele depende de um agente da justiça (delegado ou alguém ligado ao judiciário) para decidir sobre o que fazer com relação à ameaça de vingança por parte do assaltante ${ }^{12}$. O sujeito recebe o apoio de um adjuvante para realizar uma suposta volta à situação de equilíbrio, que seria o delegado conhecido, que o aconselha a matar $\mathrm{o}$ assaltante.

Assim, consideramos que não se trata de uma narrativa sobre a necessidade, nem sobre a justeza de fazer justiça com as próprias mãos. Aliás, se colocarmos a ação do sujeito da narrativa exclusivamente em termos de justiça pelas próprias mãos, estaremos de imediato procedendo a um julgamento sumário e proferindo, ao mesmo tempo, a sentença condenatória.

Procurando não prejulgar neste momento de análise, estaremos nos aproximando das vivências concretas e tornando mais fácil compreender que não se trata de um simples jogo de princípios, de saber quais são os valores corretos, ou qual é a atitude correta, racional a ser adotada. A complexidade do caso fica evidente quando mobilizamos a nossa capacidade vivencial, procurando nos colocar na situação do outro. Assim, abandonando uma atitude meramente normativa, passamos a compreender melhor as motivações dos atos que estamos analisando, e podemos alcançar a complexidade dos dilemas que enfrentamos cotidianamente.
Considero particularmente revelador dessa postura uma passagem do livro Hello Brasil! Notas de um psicanalista europeu viajando ao Brasil, do psicanalista italiano Contardo Calligaris, que serviu de base para o nosso trabalho. Na referida passagem, ele relata que frente a uma revolta de presos, que terminou com uma violenta ação da Brigada Militar do Rio Grande do Sul em 1988, com execução de presos, não houve reações de escândalo como se poderia esperar e a imprensa publicou a lista de mortos acompanhada do catálogo dos seus crimes. Calligaris relata a sua reação pessoal frente a estas execuções e a associação dos mortos a seus crimes com grande sinceridade e extrema sensibilidade:

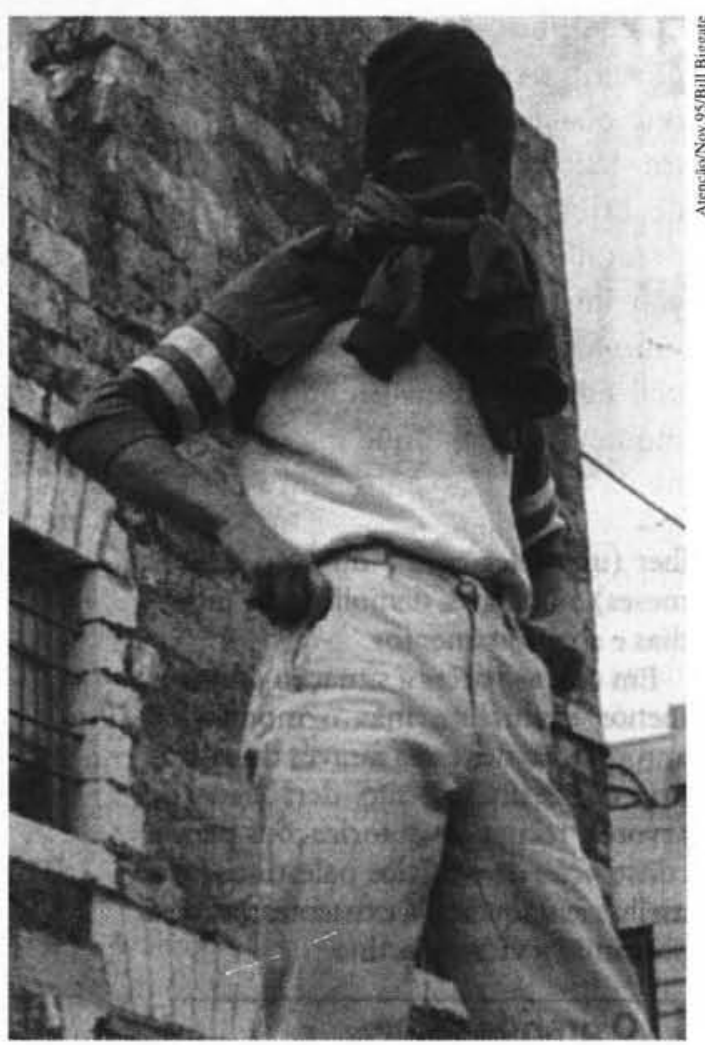

12. Notamos que quando mãe e filho são assaltados, não existe a possibilidade de vingança por parte do assaltante e mesmo assim, a mãe, ao encontrar casualmente $o$ assaltante, num outro dia, o atropela. 
"A coisa me indigna tanto menos pois eu mesmo me surpreendi a pensar que não há que se preocupar com os direitos civis de um bando de assassinos reincidentes. Surpreendi-me porque normalmente, em épocas européias, não teria espontaneamente subordinado o respeito da lei à natureza do crime do culpado, por atroz que fosse, convencido automaticamente de que o meu dever cívico está do lado do direito independentemente do fato." 13

Esta declaração tornada pública pelo próprio autor, uma pessoa reconhecida como defensor dos direitos humanos e civis, mostra uma faceta invisível, raramente admitida. A atitude politicamente correta frente a este tipo de fenômeno seria essencialmente normativa, ou seja, rechaçar a matança. Aqueles que fizessem qualquer comentário próximo daquele que nos confi- denciou ter feito o conhecido psicanalista, seriam condenados pela sua mentalidade autoritária e direitista.

Cada um de nós sabe que no cotidiano das práticas culturais a polaridade entre certo e errado não é absoluta nem constante. Muitas vezes nos encontramos frente a dilemas e os comportamentos sociais parecem mostrar-se irredutivelmente ambíguos.

A reação, digamos, nativa de Calligaris, que afirma ter agido como um brasileiro, o faz relacionar suas declarações pessoais com as cenas do caso real que discutimos no início do texto, afirmando o seu caráter revelador da sociedade brasileira, pois elas descrevem um caso que, como ele diz, si non é vero é ben trovato.

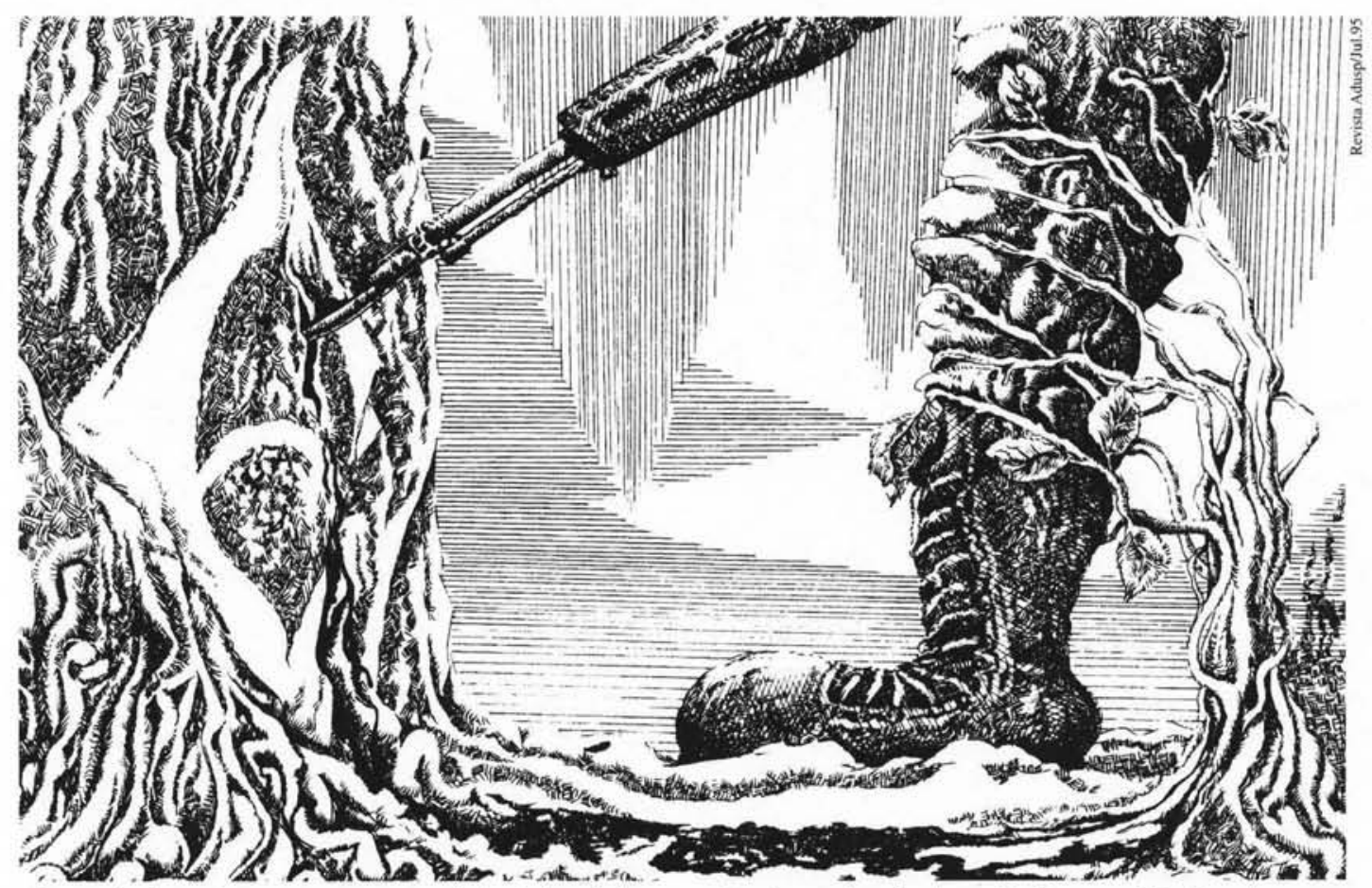

O autoritarismo impregnou-se na sociedade brasileira e manifesta-se através da confusão e conflito de valores. 
Resumo: Este artigo é o primeiro de uma série através da qual pretendemos discutir as bases culturais, atitudes e juizos que fundamentam a nossa percepção atual no campo da segurança e da justiça. Iniciamos o nosso texto mostrando que a violência é uma noção genérica e homogeneizadora que recobre diferentes fenômenos sociais. A seguir examinamos detalhadamente um caso paradigmático, que nos permite evidenciar os dilemas sociais que enfrentamos na construção de uma sociedade democrática.

Palavras-chave: violência, cultura, segurança, justiça, ética
Abstract: This article is the first of a series through which we intend to discuss the cultural basis, attitudes and judgements that support our current perception in the fields of safety and justice. We begin our text showing that violence is a generic and homogenizing notion that covers different social phenomena. We will, then, examine, in detail, a paradigmatic case that allows us to evidence the social dilemma that is confronted in the construction of a democratic society.

Key words: violence, culture, safety, justice, ethics 